\title{
A rare cause of hemoptysis: Leech infestation
}

\author{
Ben Ghezala Hassen, Snouda Salah, Ferchichi Samia, Abbes Fehmi, \\ Bechikh Imen
}

\begin{abstract}
Introduction: Hemoptysis is a medical emergency. Unusual causes may exist. We report a very rare case of hemoptysis, whose cause has proven an infestation of the respiratory mucosa by a Leech. Case Report: An 8o-year old male presented with a three-day history of hemoptysis. The patient was admitted to our intensive care unit for respiratory distress and hemodynamic instability. Endoscopic examination was performed following nasal packing under local anesthesia and oxygen. A worm was noticed adhered to the bronchial mucosa. This worm was removed under local anesthesia and identified as a leech. Conclusion: The infestation by the leech remains relatively rare. The diagnosis should be considered in the presence of unexplained hemoptysis, in patients with a recent history of drinking stream water. Endoscopy is the cornerstone in the diagnosis and the treatment of this infestation.
\end{abstract}

Keywords: Bronchial mucosa, Bronchiectasis, Hemoptysis, Leech, Tuberculosis

Ben Ghezala Hassen', SnoudaSalah², Ferchichi Samia ${ }^{3}$, Abbes Fehmi ${ }^{4}$, Bechikh Imen²

Affiliations: ${ }^{1}$ Medical Director Physician Director, Teaching Department of Emergency and Intensive Care Medicine, Zaghouan Hospital, Zaghouan, Tunisia; ${ }^{2}$ Medical Director, Teaching Department of Emergency AND Intensive Care Medicine,Zaghouan Hospital, Zaghouan, Tunisia; ${ }^{3}$ Medical Director, Department of Pneumology, Zaghouan Hospital, Zaghouan, Tunisia; ${ }^{4}$ Medical Director, Department of Cardiology, Zaghouan Hospital, Zaghouan, Tunisia.

Corresponding Author: Snouda Salah, Regional Hospital of Zaghouan, Avenue of Environment, Zaghouan1100, Tunisia. Contact Ph: +216 90269364, Fax: +216 72675772; Email: dr.snouda.rea@gmail.com

Received: 27 March 2015

Accepted: 14 May 2015

Published: 01 June 2015

\section{How to cite this article}

Hassen BG, Salah S, Samia F, Fehmi A, Imen B. A rare cause of hemoptysis: Leech infestation. Case Rep Int 2015;4:11-13.

Article ID: 100008CRINTBH2O15

$* * * * * * * * *$

doi:10.5348/crint-2015-8-CR-3

\section{INTRODUCTION}

Hemoptysis is a medical emergency. Patients die from asphyxiation or exsanguination. The most common causes are tuberculosis, bronchiectasis, and carcinoma [1]. But "unusual" causes may exist. When hemoptysis is massive or associated with respiratory failure, the patient should be supported in intensive care unit. We report a very rare case of hemoptysis, poorly tolerated hemodynamically, whose cause has proven an infestation of the respiratory mucosa by a blood-sucking worm: "A leech"!

\section{CASE REPORT}

An 80-year old male presented with a three-days history of hemoptysis. He had a history of prostate adenoma and tobacco. Clinical examination revealed a body temperature of $37.4^{\circ} \mathrm{C}$, a heart rate of $120 / \mathrm{min}$, a blood pressure of $80 / 60 \mathrm{mmHg}$, a respiratory rate of $24 / \mathrm{min}$, oxygen saturation of $90 \%$. The pulmonary auscultation objectified few wheezing. Arterial blood gas analysis revealed hypoxemia and respiratory alkalosis. Chest radiography showed a bilateral bronchial syndrome. The hemoglobin level was $8 \mathrm{~g} / \mathrm{dl}$. The patient was admitted to our intensive care unit for respiratory distress and hemodynamic instability. He was put on 
oxygen and adrenaline aerosol without improvement. Endoscopic examination was performed following nasal packing under local anesthesia and oxygen. A worm was noticed adhered to the bronchial mucosa. This worm was removed under local anesthesia and identified as a leech. It was black in color, measured about $4 \mathrm{~cm}$ and was mobile (Figure 1). After removal of the leech, bleeding stopped immediately with spectacular stabilization of respiratory and hemodynamic status.

\section{DISCUSSION}

Leeches are blood-sucking hermaphroditic parasites belonging to the phylum Annelida of the class Hirudinea [2]. Leeches are generally found in puddles of water and streams. The contamination occurs by drinking infected water, and then, leeches localize on the mucus of pharynx, tonsils, esophagus, nose or nasopharynx, trachea, lower genitourinary tract (urethra and vagina), rarely in larynx and even eyes [3]. They feed on the blood of its hosts by biting through the skin and sucking out a quantity of blood equivalent to $890 \%$ of their body weight. They secrete anticoagulants such as hirudin, which inhibits thrombin and factor IXa, and hementerin, a plasminogen activator [4]. Symptoms depend on the localization place of the leech. They may causes epistaxis and nasal obstruction if they attache the nasal cavity and nasopharynx. If the leech is found in the oral cavity, the symptoms include hemoptysis and a feeling of a foreign body inside the mouth. The localization of the leech in the larynx causes symptoms like hemoptysis, hoarseness and respiratory distress [5]. Leeches may causes gastrointestinal bleeding and severe anemia, which may require a blood transfusion

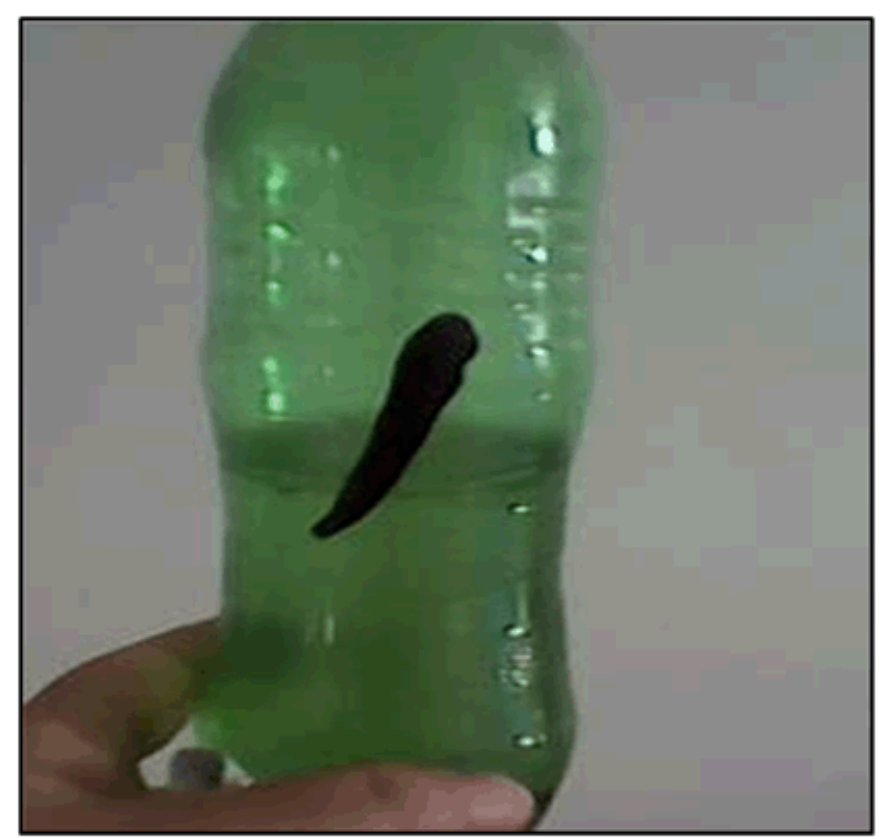

[6]. In some cases the hemoptysis may be responsible for respiratory distress and hemodynamic instability, as was the case in our patient. Endoscopy is the key examination to confirm the diagnosis and the treatment is based on the instrumental delivery of the leech. This extraction is not always easy, firstly because of its location, on the other hand due to its important link power. When the leech is found attached to the respiratory tract, it may be easily removed by using forceps. We must be very careful while removing the leech from its location; because of its slippery body surface which can easily be ruptured [7]. In our case, leech was removed safely in one piece by using forceps with the requirement of local anesthesia. Treatment involves thereafter, antiseptic and local analgesics as well as the treatment of anemia, present in almost half of cases [8].

\section{CONCLUSION}

The infestation by the leech remains relatively rare. The diagnosis should be considered in the presence of unexplained hemoptysis, in patients with a recent history of drinking stream water. Endoscopy is the cornerstone in the diagnosis and the treatment of this infestation. To avoid contamination, people living in rural areas should be informed of the complications resulted by such ectoparasites and should use natural spring water after boiling and filtering them.

$$
* * * * * * * * *
$$

\section{Author Contributions}

Ben Ghezala Hassen - Substantial contributions to conception and design, Acquisition of data, Analysis and interpretation of data, Drafting the article, Revising it critically for important intellectual content, Final approval of the version to be published

Snouda Salah - Analysis and interpretation of data, Revising it critically for important intellectual content, Final approval of the version to be published

Ferchichi Samia - Analysis and interpretation of data, Revising it critically for important intellectual content, Final approval of the version to be published

Abbes Fehmi - Analysis and interpretation of data, Revising it critically for important intellectual content, Final approval of the version to be published

Bechikh Imen - Analysis and interpretation of data, Revising it critically for important intellectual content, Final approval of the version to be published

\section{Guarantor}

The corresponding author is the guarantor of submission.

\section{Conflict of Interest}

Authors declare no conflict of interest.

Figure 1: The leech. 


\section{Copyright}

(C) 2015 Ben Ghezala Hassen et al. This article is distributed under the terms of Creative Commons Attribution License which permits unrestricted use, distribution and reproduction in any medium provided the original author(s) and original publisher are properly credited. Please see the copyright policy on the journal website for more information.

\section{REFERENCES}

1. Harrison TR, Braunwald E. Hemoptysis. In: Harrison's Principles of internal medicine. 15th ed. New York: McGraw-Hill 2001:203-6.

2. Guerrant RL, Walker DH, Weller PF. Essentials of tropical infectious diseases. Philadelphia: Churchill Livingstone; 2001. p. 607-8.

3. EbrahimRazi. Aquatic leech infestation: A rare cause of hemoptysis. Case Rep ClinPract Rev 2007;8:12527.

4. al-Hadrani A, Debry C, Faucon F, Fingerhut A. Hoarseness due to leech ingestion. J Laryngol Otol 2000 Feb;114(2):145-6.

5. Ismail I, Ozgur S, Imran S, Ferhat B, Mehmet TG. A Rare Cause of Epistaxis, Hemoptysis and Anemia: Leech in the Nasopharynx. J Med Cases 2010;1:71-3.

6. White GB. Leeches and leech infestation, In: Cook GC, Manson's Tropical Diseases. 20th ed. London: Saunders; 1998. p. 1523-5.

7. O.zdek A, Emir H, Kaptan ZK. An Unusual Cause of Adult Dyspnea and Hemoptysis: Leech Infestation of the Larynx. Journal of Ear Nose Throat and Head Neck Surgery 2008;16:138-40.

8. S, engu“l E, Bakir S, S, engu“l CA, Erdur O“. An unusual cause of epistaxis, anemia and upper respiratory tract obstruction Leeches: Report of three cases. J ClinExp Invest 2012;3:401-3.

Access full text article on other devices

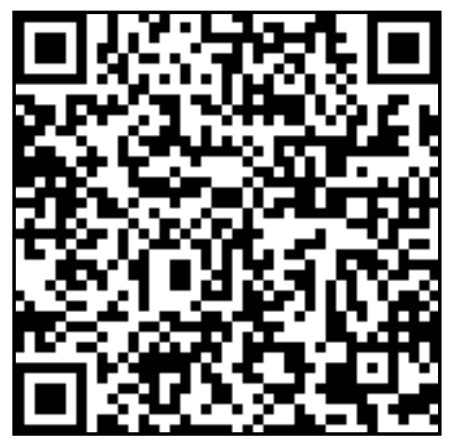

Access PDF of article on other devices

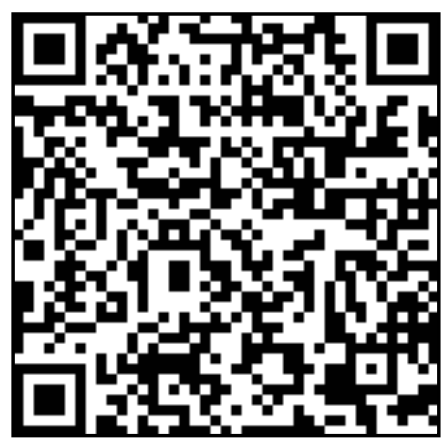

